\section{Association between use of non-steroidal anti- inflammatory drugs and risk of myocardial infarction in patients with spondyloarthritis and osteoarthritis}

Non-steroidal anti-inflammatory drugs (NSAIDs) have anti-inflammatory, antipyretic and analgesic effects and are widely used clinically for the treatment of osteoarthritis (OA), rheumatoid arthritis (RA) and many other inflammatory diseases. ${ }^{1}$ At present, NSAIDs are the first-line therapy for psoriatic arthritis and axial spondyloarthritis (SpA), ${ }^{2-4}$ but the use of NSAIDs may be related to the risk of myocardial infarction (MI). ${ }^{56}$ Recently, we read with great interest the paper entitled 'Risk of myocardial infarction with use of selected non-steroidal anti-inflammatory drugs in patients with spondyloarthritis and osteoarthritis' published online in 19 April 2018 in Annals of the Rheumatic Diseases. Dubreuil et al concluded that compared with remote use of any NSAIDs, the use of diclofenac in SpA was related to twofold to threefold risk of MI, but the use of naproxen did not increase the risk of $\mathrm{MI}$ in OA or SpA. ${ }^{7}$ Certainly, the findings of Dubreuil et al will be significant for clinicians, while there are still several questions that we would like to communicate with the authors.

First, the diagnostic criteria of MI are not clearly described in the study. According to the third universal definition of MI, ${ }^{8}$ we can diagnose the patient as MI if one of the conditions is met. (1) To detect a rise and/or fall of cardiac biomarker values (preferably cardiac troponin (cTn)) and at least one value above the 99th percentile upper reference limit (URL). (2) Cardiac death with symptoms suggestive of myocardial ischaemia and presumed new ischaemic ECG changes or new left bundle-branch block, but death occurred before cardiac biomarkers were obtained or increased. (3) Percutaneous coronary intervention correlated MI: a rise of cTn values $(>5 \times 99$ th percentile URL) in patients with normal baseline values ( $\leq 99$ th percentile URL). (4) Stent thrombosis related to MI when detected by coronary angiography. Therefore, providing a uniform and accurate diagnostic criteria for MI will help us to know the selection criteria for patients.

Second, the definition of OA is not described in this article. At present, there is no consensus about the classification criteria of OA. American College of Rheumatology (ACR) classification criteria ${ }^{9}$ and the Kellgren and Lawrence (K-L) system ${ }^{10}$ are the most frequently used criteria. The ACR classification criteria are based on clinical manifestation (pain or stiffness in joint), laboratory and radiographic aspects of OA, while the K-L system identifies and grades OA depend on radiographs. However, there are subgroups of patients who have only radiographic but not symptomatic OA and vice versa owing to the heterogeneity of $\mathrm{OA},{ }^{11}$ so it might be better to clarify the definition of $O A$ in this report.

Third, the age span of patients in the study is too large (18-89 years old). The incidence of MI is different in different age groups. According to previous study, the risk of MI among older patients was greater and the size of this population was increasing. ${ }^{12}$ Moreover, patients aged 65 years and older with MI are a heterogeneous group by age. ${ }^{13}$ The author does not seem to consider that the prevalence of MI in patients of different ages before taking medicine is not the same.

Fourth, the information about the use of NSAIDs was not shown in detail in this paper. NSAIDs play an important role in the remission treatment of $\mathrm{OA}$ so that a large number of
Table 1 International osteoarthritis diagnosis and treatment guidelines

\begin{tabular}{|c|c|}
\hline Guidelines & Recommended usage \\
\hline AAOS & $\begin{array}{l}\text { Patients with knee OA and high risk of gastrointestinal tract: topical } \\
\text { NSAIDs and non-selective oral NSAIDs combined with gastrointestinal } \\
\text { protection agents. }\end{array}$ \\
\hline AGS & Patients with local non-neuronal persistent pain: topical NSAIDs. \\
\hline EULAR & $\begin{array}{l}\text { Patients with hand osteoarthritis: topical medication is better than } \\
\text { systemic treatment. } \\
\text { Patients with knee osteoarthritis: topical NSAIDs are effective and safe. }\end{array}$ \\
\hline NICE & $\begin{array}{l}\text { Patients with knee or hand OA: to add topical NSAIDs based on core } \\
\text { therapy to relieve pain. Topical NSAIDs should be used prior to oral } \\
\text { NSAIDs, cyclo-oxygenase-2 inhibitors or opioids. }\end{array}$ \\
\hline OARSI & $\begin{array}{l}\text { Patients with knee OA: topical NSAIDs are effective adjuvant therapy } \\
\text { and alternative treatment for oral analgesic/anti-inflammatory } \\
\text { treatment. }\end{array}$ \\
\hline
\end{tabular}

AAOS, American Academy of Orthopaedic Surgeons; AGS, American Geriatrics Society; EULAR, The European League Against Rheumatism; NICE, The National Institute for Health and Care Excellence; NSAID, non-steroidal anti-inflammatory drug; OA, osteoarthritis; OARSI, Osteoarthritis Research Society International.

guidelines have provided relevant therapeutic opinions on the treatment of OA by NSAIDs and recommended topical NSAIDs as first-line drugs for OA (table 1). ${ }^{14-16}$ The authors have pointed out that some patients may take NSAIDs inconsistently, only on an as-needed basis for pain. We considered whether the participants can be divided into different subgroups according to their drug use frequency or dosage in order to avoid this limitation. Therefore, the detailed usage of NSAIDs may be of great importance.

Last but not least, many drugs are used for the treatment of $\mathrm{OA}$ at present including glucosamine drugs (such as chondroitin sulfate (CS)), corticosteroid drugs (such as glucocorticoids (GCs)) and so on. CS can significantly reduce serum total cholesterol, low-density lipoprotein and triglyceride levels, which may be associated with the risk of MI. ${ }^{17}$ Besides, GCs also may influence the risk of $\mathrm{MI},{ }^{18}$ which can be mediated by its deleterious effects on hypertension, hyperlipaemia, glucose tolerance, accelerated atherosclerosis and coagulation disturbances. ${ }^{19-21}$ How does the author rule out the effect of other osteoarthritis medications which the patients may take on MI?

We utterly respect the great contributions of the authors. Meanwhile, we would be very interested in the authors' response regarding the above issues.

\section{Jian Zhou, ${ }^{1,2}$ Ying Xiao, ${ }^{3}$ Chenxi Li, ${ }^{4}$ Tang Liu, ${ }^{1}$ Wanchun Wang ${ }^{1}$ \\ ${ }^{1}$ Department of Orthopedics, The Second Xiangya Hospital, Central South University, Changsha, China \\ ${ }^{2}$ Department of Sports Medicine Research Center, Central South University, Changsha, Hunan, China \\ ${ }^{3}$ Department of Nephrology, The Second Xiangya Hospital, Central South University, Changsha, China \\ ${ }^{4}$ Department of Clinical Medicine, School of Medicine, Shandong University, Jinan, Shandong, China}

Correspondence to Professor Tang Liu and Professor Wanchun Wang, Department of Orthopedics, The Second Xiangya Hospital, Central South University, Changsha, Hunan 410011, China; liutang1204@csu.edu.cn, wanchun.wang@csu.edu.cn

Contributors All authors were involved in the study conception, manuscript drafting and revising and final approval of the submitted version.

Funding This work was supported by the Fundamental Research Funds for the Central Universities of Central South University (Grant No. 2018zzts930), the Central South University Sports Medicine Scholarship and the National Natural Science Foundation of China (Grant Nos. 81000821 and 81672176).

Competing interests None declared.

Patient consent Not required. 
Provenance and peer review Not commissioned; internally peer reviewed.

(c) Article author(s) (or their employer(s) unless otherwise stated in the text of the article) 2019. All rights reserved. No commercial use is permitted unless otherwise expressly granted.

\section{D) Check for updates}

To cite Zhou J, Xiao Y, Li C, et al. Ann Rheum Dis 2019;78:e78.

Received 11 May 2018

Accepted 12 May 2018

Published Online First 25 May 2018

\section{SLinked}

http://dx.doi.org/10.1136/annrheumdis-2018-213771

Ann Rheum Dis 2019;78:e78. doi:10.1136/annrheumdis-2018-213752

\section{REFERENCES}

1 Kowalski ML, Makowska JS, Blanca M, et al. Hypersensitivity to nonsteroidal antiinflammatory drugs (NSAIDs) - classification, diagnosis and management: review of the EAACI/ENDA(\#) and GA2LEN/HANNA*. Allergy 2011;66:818-29.

2 Braun J, van den Berg R, Baraliakos X, et al. 2010 update of the ASAS/EULAR recommendations for the management of ankylosing spondylitis. Ann Rheum Dis 2011;70:896-904.

3 Ward MM, Deodhar A, AkI EA, et al. American College of Rheumatology/Spondylitis Association of America/Spondyloarthritis Research and Treatment Network 2015 recommendations for the treatment of ankylosing spondylitis and nonradiographic axial spondyloarthritis. Arthritis Rheumatol 2016;68:282-98.

4 Gossec L, Smolen JS, Ramiro S, et al. European League Against Rheumatism (EULAR) recommendations for the management of psoriatic arthritis with pharmacological therapies: 2015 update. Ann Rheum Dis 2016;75:499-510.

5 Lindhardsen J, Gislason GH, Jacobsen S, et al. Non-steroidal anti-inflammatory drugs and risk of cardiovascular disease in patients with rheumatoid arthritis: a nationwide cohort study. Ann Rheum Dis 2014;73:1515-21.

6 Roubille $C$, Richer $V$, Starnino T, et al. The effects of tumour necrosis factor inhibitors, methotrexate, non-steroidal anti-inflammatory drugs and corticosteroids on cardiovascular events in rheumatoid arthritis, psoriasis and psoriatic arthritis: a systematic review and meta-analysis. Ann Rheum Dis 2015;74:480-9.
7 Dubreuil M, Louie-Gao Q, Peloquin CE, et al. Risk of myocardial infarction with use of selected non-steroidal anti-inflammatory drugs in patients with spondyloarthritis and osteoarthritis. Ann Rheum Dis 2018;77:1137-42.

8 van Beek DE, van Zaane B, Buijsrogge MP, et al. Implementation of the third universal definition of myocardial infarction after coronary artery bypass grafting: a survey study in Western Europe. J Am Heart Assoc 2015:4:e001401.

9 Altman R, Asch E, Bloch D, et al. Development of criteria for the classification and reporting of osteoarthritis. Classification of osteoarthritis of the knee. Diagnostic and Therapeutic Criteria Committee of the American Rheumatism Association. Arthritis Rheum 1986;29:1039-49.

10 Kellgren JH, Lawrence JS. Radiological assessment of osteo-arthrosis. Ann Rheum Dis 1957;16:494-502

11 Zhang Y, Jordan JM. Epidemiology of osteoarthritis. Rheum Dis Clin North Am 2008:34:515-29.

12 Gillum BS, Graves EJ, Wood E. National hospital discharge survey. Vital Health Stat:13:19981-51.

13 Mehta RH, Rathore SS, Radford MJ, et al. Acute myocardial infarction in the elderly: differences by age. J Am Coll Cardiol 2001;38:736-41.

14 Combe B, Landewe R, Lukas C, et al. EULAR recommendations for the management of early arthritis: report of a task force of the European Standing Committee fo International Clinical Studies Including Therapeutics (ESCISIT). Ann Rheum Dis 2007;66:34-45.

15 Zhang W, Moskowitz RW, Nuki G, et al. OARSI recommendations for the management of hip and knee osteoarthritis, Part II: OARSI evidence-based, expert consensus guidelines. Osteoarthritis Cartilage 2008;16:137-62.

16 Zhang W, Nuki G, Moskowitz RW, et al. OARSI recommendations for the management of hip and knee osteoarthritis: part III: Changes in evidence following systematic cumulative update of research published through January 2009. Osteoarthritis Cartilage 2010;18:476-99.

17 Han LK, Sumiyoshi M, Takeda T, et al. Inhibitory effects of chondroitin sulfate prepared from salmon nasal cartilage on fat storage in mice fed a high-fat diet. Int $J$ Obes Relat Metab Disord 2000;24:1131-8.

18 Caplan L, Wolfe F, Russell AS, et al. Corticosteroid use in rheumatoid arthritis: prevalence, predictors, correlates, and outcomes. J Rheumatol 2007;34:696-705.

19 Sholter DE, Armstrong PW. Adverse effects of corticosteroids on the cardiovascular system. Can J Cardiol 2000;16:505-11.

20 Panoulas VF, Douglas KM, Stavropoulos-Kalinoglou A, et al. Long-term exposure to medium-dose glucocorticoid therapy associates with hypertension in patients with rheumatoid arthritis. Rheumatology 2008;47:72-5.

21 Brotman DJ, Girod JP, Garcia MJ, et al. Effects of short-term glucocorticoids on cardiovascular biomarkers. J Clin Endocrinol Metab 2005:90:3202-8. 